IP Periodica Polytechnica Chemical Engineering

59(4), pp. 272-276, 2015

DOI: $10.3311 /$ PPch.7571

Creative Commons Attribution (i)

RESEARCH ARTICLE

\section{Effect of Immersed Herbs on the Oxidative Stability of Edible Oils}

\author{
László Somogyi ${ }^{1}{ }^{*}$, Ágnes Gorka ${ }^{1}$, Anita Soós ${ }^{1}$, Katalin Badak-Kerti ${ }^{1}$, \\ Kata Kóczán-Manninger ${ }^{1}$, Ildikó Szedljak ${ }^{1}$
}

Received 24 June 2014; accepted after revision 12 January 2015

\begin{abstract}
The improvement of the oxidative stability of edible oils is in the focus of scientific and consumer interest. In the present work the effect of immersion of herbs in edible oils was performed and changes in oxidative stability were measured. Sage and oregano were chosen as herbs and linseed oil, corn germ oil as well as walnut oil as lipid media. Immersion parameters were 3\%, 5\%, and 7\% (w/w) herb/oil, duration: 10 days, temperature: $30^{\circ} \mathrm{C}$. Oxidative stability was measured by Rancimat test and FRAP analysis. Results showed that the oxidative stability of the highly sensitive oils -such as linseed and walnut oil-was successfully improved by immersion of herbs. Corn germ oil, which contains a high amount of tocopherols, became similarly more stable, however, only moderately.
\end{abstract}

\section{Keywords}

herbs, oxidative stability, edible oils, antioxidant capacity
${ }^{1}$ Corvinus University of Budapest, Budapest, Villányi út 29-43, Hungary

*Corresponding author, e-mail: laszlo.somogyi@uni-corvinus.hu

\section{Introduction}

Consumption of edible oils partly depends on shelf life. It is well-known that the oils considered as nutritionally beneficial are often highly sensitive to oxidation [8]. There are permanent efforts to develop methods in order to improve the oxidative stability of edible oils using natural antioxidants $[11,15]$. Of these, some Mediterranean herbs are in the focus of the investigations $[1,14]$. The simplest way to provide the edible oil with the antioxidative compounds of the herbs is the immersion of leaves into the oils [3]. Effectiveness of diffusion of the active components during dipping depends on the conditions of the procedure. Amount of the immersed herb, temperature and duration of immersion are the most important parameters.

In our research, sage (Salvia officinalis L) and oregano (Oreganum vulgare L.) were used as herbs based on the previously reported results $[1,6]$. Three edible oils were involved in the investigations, two of them were rich in polyunsaturated fatty acids (linseed oil and walnut oil) and one was rich in tocopherols (corn germ oil) [11].

\section{Experimental}

\subsection{Materials}

Dried and chopped herbs (sage and oregano) as well as linseed oil, walnut oil and corn germ oil were obtained from a local market. Edible oils were products of Solio Kft, Fadd, Hungary, sage was produced by Herbária Ltd., Budapest, Hungary, oregano was produced by Kotányi Hungaria Kft., Budapest, Hungary. Since all materials were commercially available, we could suppose that all of them satisfied the existing regulations (Codex Alimentarius Hungaricus for edible oils and spices, national regulation 4/1998 (XI. 11.) EüM as well as MSZ 20004:1984 for oregano; sage has no specific standard) and were not older than one year according to the declared shelf life. Water content of dried spices is normally less then $10 \%$, according to the usual technology [18]. Particle size varied between 0.3-0.6 cm as usual for chopped spices [5]. Samples were prepared in PET preform flasks: $100 \mathrm{~g}$ edible oil was poured into the flask and the herb was added in 3\%, 5\%, and $7 \%(\mathrm{w} / \mathrm{w})$ amounts. The preforms were sealed and kept at $30^{\circ} \mathrm{C}$ 
in dark for 10 days. Preforms were kept horizontally in order to reach a uniform distribution of spices in the oil. All settings were prepared in triplicates. After the immersion period samples and pure oils as control substances were investigated.

\subsection{Methods}

Oxidative stability was measured by Rancimat apparatus (Rancimat 743 Metrohm AG). Rancimat test is substantially a forced oxidation of the edible oils. Volatile compounds that are formed during oxidation cause changes in the conductivity of distilled water, into which the volatiles are trapped. Time-conductivity function is recorded during the test and the time for the second derivative of the function reaches the maximum which is considered as characteristic of the resistance against oxidation, called induction time. Consequently higher induction time indicates higher oxidative stability. Air flow during the test was $10 \mathrm{l} / \mathrm{h}$ and the temperature was set to $110^{\circ} \mathrm{C}$. Mean and standard deviation of the induction times were recorded [10].

The effect of antioxidant materials was characterized by the results of FRAP („Ferric Reducing Ability of Plasma”) -method. Theoretical basis of the method is that the ferri- 2, 4, 6-tripiril-Striazine (TPTZ) complex is reduced by antioxidative materials causing spectropfotometrically detectable color changes at 593 $\mathrm{nm}$ [9]. The conditions of the measurement followed the method published by Szydlowska-Czerniak (2008) [16].

Fatty acid composition of the oils was measured following the procedure of ISO 5508:1990 and ISO 5509:1990 standards. GC apparatus was HP 5890 GC System, type of the column was SGE BPX 70. Identification of the fatty acids was based on retention times.

Results were statistically elaborated using ANOVA and post hoc methods (Tukey test, Games-Howell test) by means of SPSS software package. (SPSS for Windows 20 IBM) ANOVA model involved three important parameters, namely: type of the herb, amount of the immersed herb and type of the oil. Analysis was based on 5\% level of significance.

\section{Results and Discussion}

Fatty acid profile of the investigated edible oil is summarized in Table 1.

Results that are summarized in Table 1 are in accordance with the fact that linseed oil and walnut oil are naturally rich in polyunsaturated fatty acids. Consequently these are prone to oxidation. Corn germ oil contains more saturates and monounsaturates that cause resistance against oxidation. Our results are in good agreement with other reported results [7], [13].

Modification of oxidative resistance of the investigated edible oils was detected by forced oxidation method (Rancimat) and FRAP-test.

Results of Rancimat test are shown in Fig.1 and Fig. 2.
Table 1 Fatty acid composition of the oils

\begin{tabular}{cccc}
\hline \multicolumn{4}{c}{ Fatty acid composition (\%) } \\
\hline Fatty acid & Linseed oil & Walnut oil & Corn germ oil \\
\hline $14: 0$ & 0.1 & 0.2 & n.d. \\
\hline $16: 0$ & 6.4 & 9.2 & 11.6 \\
\hline $16: 1$ & 0.1 & 0.1 & 0.1 \\
\hline $17: 0$ & 0.1 & n.d. & n.d. \\
\hline $18: 0$ & 3.6 & 3.3 & 31.9 \\
\hline $18: 1$ & 19.2 & 28.6 & 53.4 \\
\hline $18: 2$ & 47.7 & 51.5 & 0.8 \\
\hline $18: 3$ & 22.3 & 6.2 & 0.4 \\
\hline $20: 0$ & 0.1 & 0.1 & 0.3 \\
\hline $20: 1$ & 0.2 & 0.3 & n.d. \\
\hline $22: 0$ & 0.2 & 0.5 & 100 \\
\hline Total & 100 & & \\
\hline
\end{tabular}

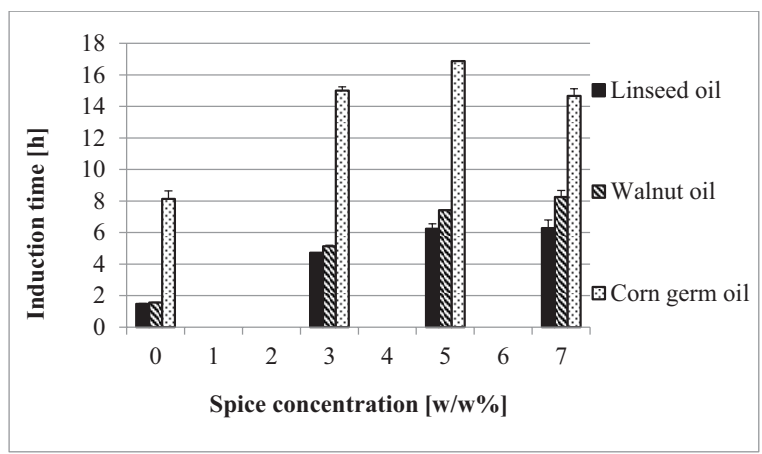

Fig. 1 Oxidative stability of sage immersed in edible oils

Figure 1 shows the changes of induction times of the edible oils in which sage was immersed. In the figure it can be seen that compared to the pure oils, immersed ones have higher induction times. The increase was consistent with the amount of the immersed herb; however, in case of corn germ oil a slight decrease was observable at $7 \%$ immersed sage. The improvement of oxidative stability was more pronounced at linseed oil and walnut oil. Corn germ oil showed the highest induction time, consequently the highest oxidative stability, but the differences from the other two oils became moderate.

Figure 2 demonstrates the results of induction times of the edible oils in which oregano was immersed. Results show that oregano increased the induction times of the oils, but this was less than the effect of sage (Fig. 1). Nevertheless the tendency of increase is clear: higher amount of immersed herb caused higher induction time. The changes were approximately linear, as it can be estimated on the basis of the results.

Summarizing these results (Fig. 1-2.) we could state that of the pure oils, corn germ oil has the highest induction time (8.14 hours), consequently corn germ oil is more stable than the other 


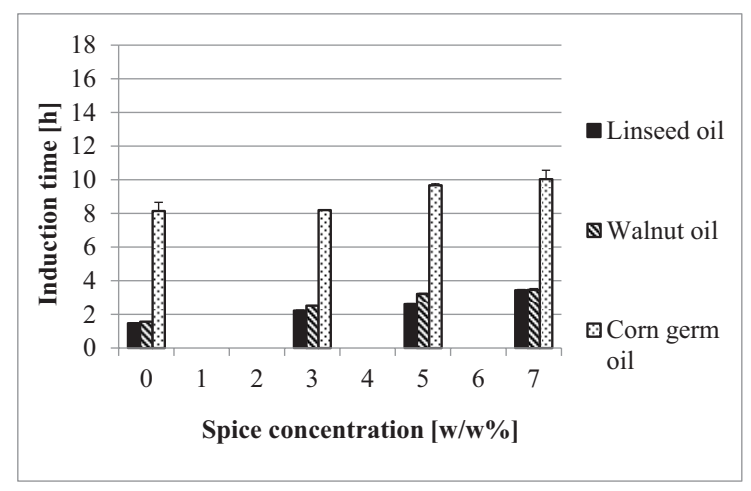

Fig. 2 Oxidative stability of oregano immersed in edible oils

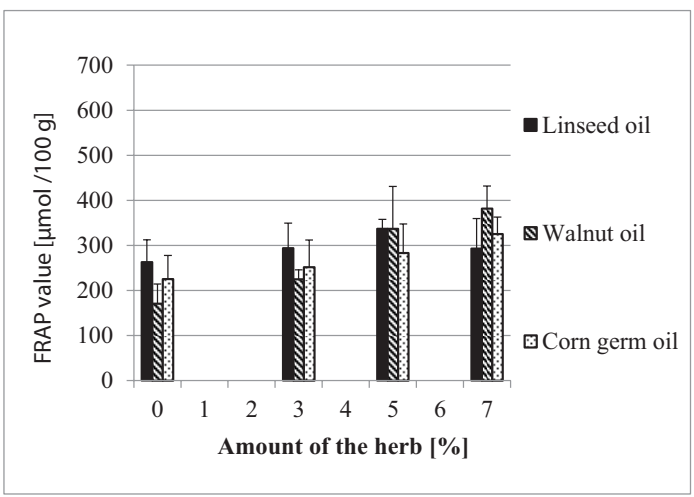

Fig. 4 Oxidative capacity of oregano immersed in edible oils two (1.48 h of linseed oil, $1.57 \mathrm{~h}$ of walnut oil). These findings are in accordance with other scientific results [4]. It can be stated furthermore that herbs were able to improve oxidative stability of the oils via increasing the induction times. The rate of increase in induction time correlated with the amount of immersed herb: more immersed herb caused higher induction time.

Regarding the first factor (type of the herb) we found that the beneficial effect of sage was more pronounced than the effect of oregano. Effect of the amount of immersed herb was more or less predictable. More herb caused mostly higher induction time. Differences were observable by the oil types too. Improvement of the oxidative stability was stronger at linseed oil and walnut oil and moderate in the case of corn germ oil.

Changes in antioxidative capacity of the oils were measured by FRAP-method. Results of the measurements are summarized in Fig. 3. and Fig. 4.

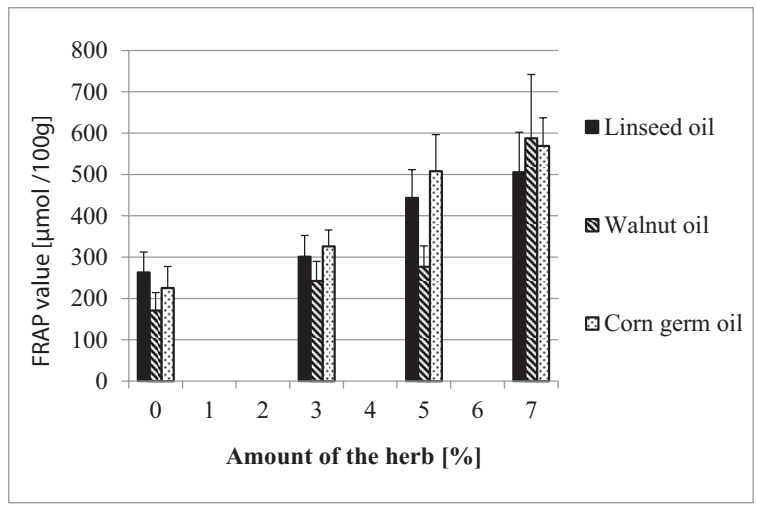

Fig. 3 Oxidative capacity of sage immersed in edible oils

Results shown in Fig. 3 demonstrate that FRAP-values increased by immersion of sage. Increase correlated with the amount of the immersed herb. However, of the pure oils walnut oil showed the least FRAP-value, consequently the least antioxidative capacity, it became the highest if the rate of the immersed herb was 7\%. The tendency of the changes of FRAP-values was non-linear.

Figure 4 presents the result of FRAP-test of the oils in which oregano was immersed. Results in Figure 4. show that oregano caused increase in FRAP-values i.e. antioxidative capacity at each samples. This was consistent in case of walnut oil and corn germ oil, but the FRAP-value of linseed oil decreased if the immersed herb was 7\%. Tendency of the changes was more or less linear.

Results in Fig. 3 and in Fig. 4 show that of the pure oils linseed oil has the highest antioxidative capacity. The next highest FRAP value belongs to the corn germ oil and the lowest to the walnut oil. However, differences are not large, results indicate that FRAP is not in close correlation to the amount of typical antioxidative compounds such as tocopherols. It is well-known that corn germ oil is outstanding in tocopherol content, but our results proved that it has moderate FRAP value.

Regarding the effect of the type of the herb, it could be established that sage generally caused more powerful increase in FRAP-values than oregano. The difference was detectable regardless of the type of the oil at the same concentrations (amount of the immersed herb).

Results proved the effect of the amount of the immersed herb too. Generally higher amount of herb caused higher FRAP value. The increase was moderate in case of oregano and a slight decrease was observable at 7\% immersed herb. The effect was more pronounced in case of sage. Even at $3 \%$ of immersed sage FRAP value increased by $15-45 \%$ and at $7 \%$ the original value became two-threefold.

Differences regarding the type of the oils were detectable too. Comparing the oils we could state that higher FRAP-values were found in the case of walnut oil. The difference was highest in case of samples treated with $7 \%$ herbs.

Results of the statistical analysis are summarized in Table 2.

Results of the statistical analysis show that the single factors, the two-level interactions and the three-level interactions have significant effect on the measured characteristics: induction time and the antioxidative capacity (FRAP-value). Considering the calculated p-values it is seen that the type of the herb and the amount of the immersed herb highly effected both induction time and FRAP-values. The least strong (however significant) effect was observed in case of three-level interaction.

Results clearly show that immersion of spices in edible oil is a possible way to improve the oxidative resistance of edible oils. However, antioxidative compounds of the herbs were not measured. Increase in induction times and FRAP values indicate 
Table 2 Results of the statistical analysis

\begin{tabular}{|c|c|c|c|c|c|c|c|}
\hline \multirow[b]{2}{*}{ Measured characteristic } & \multicolumn{7}{|c|}{ Effect } \\
\hline & \multicolumn{3}{|c|}{ One level } & \multicolumn{3}{|c|}{ Two level } & $\begin{array}{c}\text { Three level } \\
\text { AxBxC }\end{array}$ \\
\hline Induction time & $* * *$ & $* * *$ & $* * *$ & $* *$ & $* * *$ & $* * *$ & * \\
\hline
\end{tabular}

Abbreviations: A: Type of the oil, B: Type of the herb ,C: Amount of the immersed herb

$*: \mathrm{p}<0.05 ; * *: \mathrm{p}<0.01 ; * * *: \mathrm{p}<0.001$

that antioxidative materials diffused into the oils. Results proved that all the three parameters that were involved in the statistical analysis caused a significant effect on the oxidation resistance. Of the herbs sage proved to be more effective than oregano. It is interesting because oregano contains more essential oil than sage [4]. Essential oils of the herbs consist mostly terpenes, but there is a strong difference between the individual compounds. The main components of oregano are: $\gamma$ - terpinene, carvacrol, linalool, $\alpha$-terpinene and sabinene. Sage contains mostly 1.8 cineole, camphor, $\beta$-caryophyllene, viridiflorol, $\beta$-thujone [17]. Different terpinenes may cause different changes in antioxidative properties. Other reported findings show that total polyphenols in sage are higher than in oregano [12].

The amount of the immersed herb was the second important factor which caused moderate increase in oxidative stability and antioxidant capacity. Results were in good agreement with other reported findings $[3,16]$.

\section{Conclusions}

The above discussed results proved that the applied methods were suitable to detect the effect of immersed herbs on the oxidative stability of the investigated oils. As a general conclusion we could state that herbs increased the oxidative resistance of the oils. The beneficial effect depends on the amount and the type of the immersed herb as well as the characteristics of the oil. From our results we could conclude that the effect is stronger in case of oils which are rich in polyunsaturated fatty acids, consequently sensitive for rancidity. This was found both during Rancimat test and FRAP measurements. The effect is moderate on oils which contain antioxidative compounds such as tocopherols. This finding is probably due to the principle of the FRAP method. FRAP measures the ferric-reducing capability of the materials which is not in close correlation to the lipophilic antioxidants. The same result was reported by other authors [2].

\section{Acknowledgement}

This work was supported by the TÁMOP 4.2.1./B09/01/ KMR/2010-0005 project.

\section{References}

[1] Alves-Silva, J. M., Dias dos Santos, S. M., Pintado, M. E., Pérez-Álvarez, J. A., Fernández-López, J., Viuda-Martos, M. "Chemical composition and in vitro antimicrobial, antifungal and antioxidant properties of essential oils obtained from some herbs widely used in Portugal." Food Control. 32. pp. 371-378. 2013. DOI: 10.1016/j.foodcont.2012.12.022

[2] Apak, R., Güçlü, K. K., Demirata, B., Özyürek, M., Çelik, S. E., Bektaşoğlu, B., Berker, K. I., Özyurt, D. "Comparative evaluation of various total antioxidant capacity assays applied to phenolic compounds with the CUPRAC assay." Molecules. 12. pp. 1496-1547. 2007. DOI: $10.3390 / 12071496$

[3] Estévez, M., Ramírez, R., Ventanas, S., Cava, R. "Sage and rosemary essential oils versus BHT for the inhibition of lipid oxidative reactions in liver pâté." Food Science and Technology. 40 (1). pp. 58-65. 2007. DOI: 10.1016/j.lwt.2005.07.010

[4] Exarchou, V., Nenadis, N., Tsimidou, M., Gerothanassis, I. P., Troganis, A., Boskou, D. "Antioxidant activities and phenolic composition of extracts from Greek oregano, Greek sage, and summer savory." Journal of Agricultural Food Chemistry. 50 (19). pp. 5294-5299. 2002. DOI: $10.1021 / \mathrm{jf020408 \textrm {a }}$

[5] Farooki, A. A., Sreeram, B. S., Srinivasappi, K. N. "Cultivation of Spice Crops." Universities Press. 2005.

[6] Fasseas, M. K., Mountzouris, K. C., Tarantilis, P. A., Polissiou, M., Zervas, G. "Antioxidant activity in meat treated with oregano and sage essential oils." Food Chemistry. 106 (3). pp. 1188-1194. 2008. DOI: 10.1016/j.foodchem.2007.07.060

[7] Firestone, D. "Physical and chemical characteristics of oils, fats and waxes." US FDA Washington D.C. 2006.

[8] Gunstone, F. D. "Vegetable Oils in Food Technology: Composition, Properties and Uses." Blackwell Publishing Ltd. 2011.

[9] Huang, D. J., Ou, B. X., Prior, R. L. "The chemistry behind antioxidant capacity assays." Journal of Agricultural and Food Chemistry. 53. pp. 1841-1856. 2005. DOI: 10.1021 jff030723c

[10] Matthäus, B. W. Determination of the oxidative stability of vegetable oils by rancimat and conductivity and chemiluminescence measurements. JAOCS. 73 (8). pp. 1039-1043. 1996. DOI: 10.1353/jsh/29.4.1039

[11] Michotte, D., Rogez, H., Chirinos, R., Mignolet, E., Campos, D., Larondelle, Y. "Linseed oil stabilisation with pure natural phenolic compounds." Food Chemistry. 129. pp. 1228-1231. 2011. DOI: 10.1016/j.foodchem.2011.05.108

[12] Nagy, T., Solar, S., Sontag, G., Koenig, J. "Identification of phenolic components in dried spices and influence of irradiation." Food Chemistry. 128. pp. 530-534. 2012. DOI:10.1016/j.foodchem.2011.03.037

[13] O'Brian, R. Fats and Oils - Formulating and Processing for Applications. 1998.

[14] Pokorny, J., Yanishlieva, N., Gordon, M. H. "Antioxidants in Food." Taylor \& Francis. 2001. DOI: 10.1533/9781855736160 
[15] Rudnik, E., Szczucinska, A., Gwardiak, H., Szulc, A., Winiarska, A. "Comparative studies of oxidative stability of linseed oil." Thermochimica Acta. 370 (1-2).pp. 135-140. 2001. DOI: 10.1016/s0040-6031(00)00781-4

[16] Szydłowska-Czerniak, A., Karlovits, Gy., Dianóczki, Cs., Recseg, K., Szłyk, E. "Comparison of Two Analytical Methods for Assessing Antioxidant Capacity of Rapeseed and Olive Oils." JAOCS. 85. pp. 141149. 2008. DOI: 10.1007/s11746-007-1178-6
[17] Wojdyło, A., Oszmianski, J., Czemerys, R. "Antioxidant activity and phenolic compounds in 32 selected herbs." Food Chemistry. 105. pp. 940-949. 2007. DOI:10.1016/j.foodchem.2007.04.038

[18] Yiu, H. (ed.) Handbook of Food Science. Technology and Engineering Vol 3. CRC Press. 2006. 